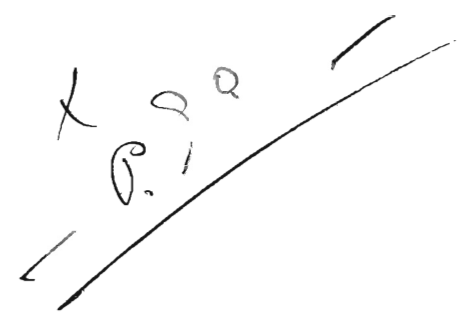

\title{
DIREITO INDUSTRIAL
}

I. Importancia e objecto do direito industrial.

II. O seu desenvolvimento na edade contemporanea.

III. A sua especialidade na encyclopedia juridica.

IV. A propriedade industrial.

V. Esboço historico da propriedade industrial no Brazil.

VI. Fontes do direito industrial brazileiro.

IMPORTANCIA E OBJECTO DO DIREITO INDUSTRIAL

1 -Ao direito industrial, importante ramificação do direito privado, destina-se na evolução juridica futuro grandioso. Basta ponderar se que o seu progresso que tem tomado extraordinario incremento a contar da segunda metade do seculo passado, caminha parallelamente com o crescente desenvolvimento da industria. Dest'arte, em breve trecho, especialidade tão fecunda ha de impôr a sua inclusão no programma official dos institutos de ensino juridico do Brazil, como já vai acontecendo noutras nações cultas. 
2.-Não acóde, pois, prematura a solicitude dos jurisconsultos em applicar detida attenção a este ramo de estudos, de modo a fazel-o progredir não menos acceleradamente do que o exige a maravilhosa expansão da industria nos tempos que vão correndo.

3.-A importancia do direito industrial evidencia-se do simples enunciado do seu objecto, a saber -o conjuncto de principios e normas juridicas que regulam a produç̧ão da riqueza pelo trabalho e as relações sociaes oriundas desse facto. (I)

4.-Não cabe em nosso proposito indagarmos neste momento - se o direito industrial é um ramo do direito civil, ou mesmo do direito privado, ou se deve de preferencia ser considerado uma divisão do direito geral; por isso que participa ao mesmo tempo, quanto algumas das suas relações, da natureza do direito publico e da do direito privado, e tambem por não se caracterisar, como o direito civil, pelo cunho da influencia mesologica, approximando-se antes, neste particular, á feiçầa quasi cosmopolita do direito mercantil.

Tal indagação, méramente especulativa, offerece margens para longas controversias, mas de puro interesse escolastico.

5.-Basta accentuarmos que, sem prejuizo da autonomia propria, o direito industrial, que mal acaba de conquistar a sua individualidade e tem apenas de-

(1) A definição que formulamos affigura-se-nos preferivel, por mais comprebensiva, a esta de Renouard, Droit Industr. Cap. I in fine: "Le droit industriel embrasse les rapports légaux et juridiques qui se créent entre les hommes par la production des choses et par l'application des choses aux services humains".

Muito se approxima da nossa a definição adoptada por Humberto Pipia, nas suas Nozioni di Diritto Industr. Cap. I n. 4.': '. .Diritto industriale deve ritenersiil complesso delle norme che regolano i rapporti giuridice inerenti ella produzione economica, e sorgenti a causa di essa tra le persone-e tra esse e le cose". 
lineado área territorial e fronteiras no mappa geral das disciplinas juridicas, se elitrelaça com as outras ramificaçǒes co-irmãs da mesma sciencia, dá-lhes e aufere dellas subsidios e tem com ellas caracteres communs e pontos differenciaes. Como, aliás, poderia a especie isentar-se das analogias que constituem o. genero?

- 6.-Assim como o direito commercial tem por objecto as nюrmas juridicas reguladoras da circulação das riquezas e colhe, para a sua formação, pingues elementos da economia politica, assim tambem o direito industrial haure subsidios de outro capitulo da mesma sciencia, o da producção das riquezas.

7.-O trabalho é a fonte mais fecunda da producção e, por isso, o primeiro factor da riqueza social. Ora, que é a industria, considerada em sua substancia, a não ser o trabalho elevado á mais alta potencia ? Ainda esse conceito addiciona-se aos que ahi ficam, em affirmação da subida importancia do direito industrial.

\section{I}

O. DESENVOLVIMENTO DO DIREITO INDUSTRIAL NA EDADE CONTEMPORANEA

8.-Unico em sua essencia, subjectivamente considerado, torna-se multiplo o direito nas suas modalidades, e estas se desenvolvem na razão directa do progressivo incremento do objecto a que se applicam.

Nada mais comprehensivel que esse facto.

A evolução natural em cada ramo da actividade humana suscita novas situações juridicas que, por sua vez, reclamam normas reguladoras. 
9.-Ora, a ninguem é dado desconhecer a prodigiosa expansão que tem tido a industria, a grande industria principalmente, desde meados do seculo XIX, e o seu incessante e maravilhoso progresso nesta quadra em que vivemos. Com a invenção de numerosos machinismos, com a substituição do braço huınano e da força animal pelo poder e a celeridade das applicações mechanicas, avultou assombrosamente a produç̧ão industrial e com ella concurrentemente a actividade intellectual do traballhador, a associação de capitaes e a tormação de agglomerações de operarios. Todos estes factores congregados a produzirem incessantemente procuram com solicitude mercados consumidores para a collocação dos seus productos industriaes.

10.--D'ahi, necessariamente, o apparecimento de novas relaçóes pessoaes e reaes reclamando a definição de preceitos peculiares, reguladores e a formação e desenvolvimento de um novo codigo-o do direito industrial.

Surge assim e assim se manifesta no estudo da sciencia juridica, uma especialidade moderna, cuja esphéra se amplia diariamente e cuja importancia, já consideravel, maior se annuncia para o futuro.

11.-E' digna de nota sobre a preponderancia hodierna do direito industrial a seguinte bellissima pagina do eminente Pouillet: (2)

"Já se vão os tempos em que o advogado, sequestrado nas abstraç̧ões do direito vivia estreitamente emparedado entre o Digesto, o Codigo Civil e a Jurisprudencia, inclinado sobre Cujaccio, Bartholo ou Pothier. Presentemente, nas faculdades de direito

(2) R. LAfon, Pour devenir avocat, pag. 108. Este interessante opusculo faz parte, e com justiça, da preciosa collecção "Les livres d'or de la science". 
como em toda a parte algures, o ensino alargou-se, vivificou-se, rejuvenesceu. $\mathrm{O}$ estudo do direito romano ficou mais especialmente reservado para os que se destinam ao magisterio. Em compensação, crearam-se novas cadeiras, por exemplo, para o ensino do direito internacional e do direito industrial. Está nova disciplina impunha-se e o numero, sempre crescente, das theses apresentadas todos os annos com a approvação dos lentes sobre assumptos tirados deste ensino, mostra perfeitamente que está alli uma parte consideravel do direito moderno.

$\mathrm{E}$ demais quem se enganaria? A industria, filha da sciencia, tomou em todos os paizes nas preoccupações humanas lugar preponderante. Ella tem transfigurado o mundo. Não é sómente o vapor dominado, o gaz hydrogeneo escravisado; é a electricidade circulando mysteriosa ao redor de nós e levando á toda parte a luz, a energia e a vida. As forças da natureza, até hoje inutillisadas e improductivas, a electridade as transporta e applica-as á distancia. Basta um gesto para expellir a noite; toca a gente um botão e logo toda a casa, a cidade toda se illumina; um outro gesto, e a casa, a cidade voltam a remer. gulhar-se na obscuridade.

Admiravamos hontem a electricidade transmittindo de $u m$ extremo ao outro do mundo, num instante, com a celeridade do relampago o nosso pensamento, e permittindo-nos communicar, por um fio, até além dos mares. Era extraordinario; dá se hoje maravilha maior. Uma palavra proferida diante de uma caixinha de madeira é immediatamente repetida a cem leguas com a inflexão da voz que a pronunciou, e vai d'um labio amigo a um ouvido amigo. As palavras mesmas com a sua entoação e o timbre da voz são fielmente registradas, depois reproduzidas á vontade com aquelle 
mesmo sotaque e aquella mesma entoação. Já não ha trévas; já não ha distancia; a propria morte está vencida; pois aquelle que já não existe e cuja bocca se enregelou, ainda nos falla! Oh maravilha!

$\mathrm{E}$ tudo isto, senhores, reflecti bem, é um começo, è uma aurora; o dia surge lentamente sobre um horizonte que prenuncia deslumbramentos sem fim.

\section{III}

A ESPECIALIDADE DO DIREITO INDUSTRIAL NA ENCYCLOPEDIA JURIDICA

12.-Os elementos basicos do direito industrial outros não são senão os proprios principios fundamentaes do direito commum. Nesse conceito geral assentam, portanto, as raizes da nova especialidade juridica. Ainda mais. Grande copia das normas legaes reclamadas pelas relações sempre crescentes da expansão industrial acham-se já, em principio, consa. gradas no direito vigente, embora esparsas no vasto corpo da legislação. Impõe-se portanto ao jurisconsulto colhel-as aqui e acolá, coordenal-as e consolidal-as mediante systema scientifico, assim como ao legislador desenvolver esses principios geraes em disposições especiaes, completal-os, preenchendo as lacunas que se verificarem e instituindo as innovações que o progresso tenha aconselhado.

13.-Este trabalho, parallelo com o fecundo subsidio da jurisprudencia dos tribunaes e as luzes que irradiam da legislação dos ouitros póvos cultos, tornará menos ardua ao legislador patrio a codificação do direito industrial, não menos necessaria, no estado 
actual da cultura juridica, do que a do direito commercial, de cujos beneficios fruimos desde 1850 .

14. - Todos os ramos do direito publico e privado, e bem assim a sciencia economica, hão de contribuir, em proporções diversas, com avultada ou diminuta copia de materiaes para esse edificio scientifico.

15.-Assim, o direito civil proporcionar-lhe-á, como proporciona presentemente ao estudo do direito industrial, os seus preceitos e dispositivos sobre a capacidade das pessoas, a garantia da propriedade e as suas transmissões, a theoria das obrigações, in clusive a satisfacção devida ex-delicio ol quasi exdelicto por violação de direitos industriaes e por accidentes de trabalho.

16. - Ao direito commercial pedirá a nova especialidade juridica o fecundo subsidio, que ora the presta, na deficiencia de preceitos privativos á industria, quanto á constituição de sociedades, locação de serviços e diversos outros contractos, e não menos sobre a propriedade por invenção, occupação ou transferencia, de nome commercial, firmas, razões de commercio, e o respectivo exercicio, transmissão e perda; e sobre a concurrencia desleal, as falsas indicações de proveniencia, etc., etc.

17 - A despeito da applicabilidade de alguns preceitos communs nas relações de direito commercial e nas de direito industrial, nem assim se confundem essas duas sub-divisões do direito privado. O direito commercial tem por objecto, na phrase de Pipia, a funcção da mediação, regulando as relações juridicas derivadas da interferencia especulativa entre a producção e o consumo, dirigida a effectuar ou facilitar a troca da riqueza; o direito industrial ao contrario refere-se ao estado anterior a essa troca; a saber ao 
momento da sua producção, regulando as relações juridicas que á mesma producção se referem ou nella se comprehendem (3).

18.--Com as instituições de direito penal relaciona-se a nova disciplina juridica, já na parte em que aquelle direito commina disposições repressivas contra os violadores da propriedade industrial; já quando acauteld a liberdade do trabalho, ampara os trabalhadores contra quem lhes queira impor o trabalho ou tenha a pretenção de lh'os vedar ou cercear; já, finalmente, quand̆o dispõe sobre abusos por occasião das grèves e o exercicio de certas profissões $\mathrm{e}$ industrias que interessam a vida, a segurança e a saude publicas.

19.--Não são indifferentes á formação do direito industrial os principios do direito publico, do direito administrativo e da sciencia da administração, relativos á liberdade de industria, á garantia da propriedade, ao direito de reunião e de associação, de locomoção e de transportes, á localisação dos estabelecimentos industriaes, ao regimen das terras, das minas e das aguas, aproveitamento e exploração da força hydraulica, do vapor e da electricidade.

20.-A economia politica e a legislação fiscal tambem interessam de perto á prosperidade e á vida das industrias, mórmente no tocante ás tarifas aduaneiras e ao systema tributario interno, cuja applicação aconselhem em vista das condições do paiz, ou inspirem ao legislador. Não podem, portanto, deixar de exercer influencia sobre a evolução das normas juridicas referentes á industria.

21.-O direito processual concorre com preciosa contribuição para a formação da nova individualidade que ora apparece entre as sciencias juridicas.

(3) U. Pipia, Obr. cit., pag. 3. 
Ainda que sob as antigas roupagens das leis e praxes do processo, os interesses industriaes começam já a ser acautelados pelo legislador moderno com a protecção de algumas acções peculiares, crimes ou civeis, e de diligencias, ora administrativas ora judiciaes, assecuratorias de direitos ou preliminares de acçãn.

22. -O direito internacional, finalmente, é mais que uma das fontes subsidiarias do direito inclustrial; é fonte essencial delle. Nem outro caracter se lhe póde reconhecer, ao menos nos paizes que, como o Brazil, fazem parte da União Internacional para a Protecção da Propriedade Industrial (4).

Os direitos e obrigações resultantes das clausulas de tratados e convenções diplomaticas livremente, celebradas e legalmente ratificadas e promulgadas, incorporaram se na legislação patria e fazem parte do nosso direito industrial.

23.-Derivado de todas estas fontes diversas, posto que não heterogeneas, nem assim o direito industrial em seu conjuncto pode ser acoimado de amalgama de elementos hybridos sem cohesão e sem systema. Domina-o, ao contrario, a unidade de umpensamento geral, coherente com a natureza do seu objecto e que se acha immanente em cada uma das suas instituições.

Este caracter substancial da nova individualidade scientifica, que ora reclama o direito de cidade no dominio dos estudos juridicos, nasce-lhe do fito constante de adoptar ou prescrever aquellas normas, conformes á justiça e á equidade, reguladoras dos interesses da industria.

(4) A convenção assignada em Paris a 20 de Março de 1883, pela qual o Brazil e outros Estados se constituiram enı "União para a Protecção da Propriedade Industrial", foi promulgada entre nós pelo Decreto n. 9.233 de 28 de Junho de 1884. 
DA PROPRIEDADE INDUSTRIAL

24.-A locução-propriedade industrial, de mo. derna applicação, não adquirio ainda na technolngia juridica accepção certa e invariavel.

2ว.-Nenhum jurisconsulto ainda lhe deu nem procurou dar-lhe a noção exacta e verdadeira, observa Maillard de Marafy (5); e muitos são os que the negam a idoneidade, contestando o caracter de propriedade a direitos que se não concretisam sobre cousas materiaes. ${ }^{(6)}$

A Convenção de Paris de 1883 não sómente fugio da difficuldade, procedendo por enumeração, como ainda com essa mesma enumeração, desvirtuou manifestamente ó conceito juridico da propriedade industrial ( 7 ).

26. - Nota-se nesse texto visivel confusão entre productos industriaes e propriedade industrial, e sorprehende que tal reparo tenha escapado ao espirito agúdo de Pipia e á criteriosa analyse de Maillard de Marafy, quando ao mesmo se referem.

Certo, os productos da agricultura, da pomicultura, pecuaria, fontes mineraes, etc., podem ser equiparados aos propriamente da industria restricto sensu; mas nem estes nem aquelles, com o serem productos industraes, constituem objecto de propriedade industrial.

(5) Maillard de Marafy, Grand Diction. de la Propr. Indust. v." "Propriété Industrielle."

(6) Renouard, Droit Industr., pag. 366 e seguintes; Braun, Trait- des marq. de fabr. n. 10 ; Moïse AMar, Dei nomi, dei marchi, n. 20 .

(7) 0 art. 1.' do Protocollo de encerramento dessa Convenção assim dispõe: "As palavras-propriedade industrial-devem ser entendidas em sua accepção mais lata, no sentido de se applicarem nâo só aos productos da industria propriamente dita, mas egualmente aos productos da agricultura (vinhos, cereaes, fructas, gado, etc.) e aos productos mineraes entregues ao commercio (aguas mineraes, etc.)" 
A propriedade que sobre elles se exerce é a de direito commum ou, seja, de direito civil. Nada ella tem de peculiar que a submetta quanto á sua origem, $\epsilon$ xercicio e disposição, aos preceitos especiaes do direito industrial.

A propriedade industrial não tem por objecto productos materiaes da industria, mas direitos industriaes (8).

27 - Quem adquire por compra ou outro titulo egual producto industrial alheio, pode delle fazer o uso que lhe approuver, inclusive destruil-o. O direito de propriedade assim havido comprehende todos os elementos do dominio, synthetisado na formula da legislação romana-uti, frui et abuti.

Se, porém, o objecto vem revestido de uma marca que the mencione a origem da produç̧ão, continúa a adquirente a poder usar delle e do respectivo signal a - sua vontade, inclusive vendel-o ou destruil-o; não pode, sómente, reproduzir, para fim mercantil, o objecto ccm a mesma marca que trazia, nem tão pouco exercer qualquer exploração lucrativa por meio do alludido signal, digamos marca; por exemplo, se a marca era apposta a um envolucro ou recipiente, não será licito utilisar-se de um ou de outro para envolver ou conter mercadoria analoga, mas de origem diversa.

28.-Outro exemplo. Se o adquirente houve a propriedade de um producto industrial de invenção alheia, está no direito de dar ao mesmo o destino que the parecer, inclusive o de lançal-o ao fogo. Parece que,

(8) A. Ostertifth, Lehrbuch des Gewebl. Rechtsschutzes, 1908, pg. 9, ibi: "Invenções e modelos (propriedade industrial) são creações que possuem existencia real; bens com valur proprio e independente do objecto a que se applicam. Ėstes bens foram creados peln esforço intellectus l do seu inventor. - São objectos do direito industrial - as invenções e modelos (marcas) como cousa incorpurea, bens immateriaes. 0 conteúdo representa o gozo economico da cousa. 
com razão maior, ser-lhe-ia licito fazer com o proprio trabalho ou a expensas proprias outro objecto egual e lucrar com a venda delle. Isto, porém, lhe é vedado por attentatorio de direito alheio, por offender á propriedade industrial do inventor; assim como, na hypothese precedente, o uso indevido da marca alheia tambem seria attentado á propriedade industrial do dono da marca.

29.-Que corollarios defluem dos exemplos que ahi ficam? Os' seguintes.

I $^{\circ}$ A propriedade industrial não se identifica com a do producto da industia;

$2 .^{\circ}$ * A propriedade industrial não se objectiva numa cousa, num producto material; é, antes, um diveito, uma propriedade immaterial;

$3 .^{\circ}$ A propriedade sobre os productos materiaes da industria é de direito civil; sómente a marca respectiva, que é de uso exclusivo, constitue propriedade industrial; nas invenções que interessam á industria a propriedade industrial é um direito de autor; consiste no monopolio da reproducção.

30.-Dissemos a pouco, reproduzindo aliás autorisado asserto, que nenhum escriptor conhecido havia, nem sequer, tentado definição scientifica de propriedade industrial. Não retiramos a expressão. Accrescentaremos, todavia, que encontramos, talvez com visos de definiçâo, esta prolixa noção num autor italiano (9):

- A propriedade industrial serve para designar o direito exclusivo para o autor de uma descoberta ou de uma nova invenção de aproveitar-se della, para um fabricante ou commerciante de servir-se de uma

(9) Esperson, La propr. industr., etc. n. 1. 
marca, de um nome, de uma designação pessoal propria para distinguir os seus productos dos de outros fabricantes ou commerciantes que exerçam a mesma industria ou o mesmo commercio, de valer-se de um desenho, de um modelo de sua invenção."

31.-Fugindo dessa diffusa noção, destituida dos requesitos de um definiçâo scientifica, o illustre jurisconsulto, ao qual já nos temos referido, Pipia, incorre por demais conciso e transcendente, na pecha obscuro. Eis como elle se exprime: "Propriedade industrial, na sua verdadeira e natural comprehensão, é a extrinsecação objectiva da actividade da empresa industrial. •( ( o)

Comprehendeu bem o leitor? - Nem nós tão pouco.

Em additamento explicativo (e com razão procura explicar-se), diz em seguida o mesmo jurisconsulto: "Ella (a propriedade industrial) abrange, por conseguinte, tantc a cousa que é o producto immediato da industria, a mercadoria, como os direitos que lhe tutelam mediatamente a livre e pacifica producção e subsequente introducção na massa circulante dos bens; como tambem os direitos inherentes á invenção ou nova forma dos productos, mediante os privilegios industriaes, e os desenhos e modelos de fabricas; os direitos inherentes á garantia da origem dos productos mediante os nomes e as marcas de fabrica; os direitos inherentes á liberdade da produç̧ão, mediante os syndicatos, e a repressão da concorrencia desleal etc.»

32.--Não obstante o respeito devido ao illustre jurisconsulto industrialista, parece-nos inexacto na primeira parte e obscuro na segunda o seu conceito de propriedade industrial.

Basta ponderar, para que justificada fique a nossa repulsa, que a noção de Pipia inclúe na categoria de

(10) PiPIA, obr. cit., pag. $6^{\circ}$ 
propriedade industrual não sómente os productos da industria (que são propriedade de direito commum), mas tambem-os direitos inherentes á liberdade de produção.

Longe do nosso espirito a idéa de contestar a legitimidade desses direitos á liberdade de producção, amparados mediante syndicatos e pela repressão da concorrencia desleal. O que, sim, não comprehendemos é que elles constituam propriedade.

Não duvidamos que o pensamento de Pipia contenha um fundo de verdade, mas força é convir que está revestido de defeituosa roupagem.

33. - Ainda por via de enumeração, aliás incompleta, dão-nos Goujet et Merger a seguinte noção de propriedade industrial: "Direito exclusivo para um fabricante de se utilisar de uma marca, de um nome, de uma designação especial que distingam os seus productos dos de outros fabricantes que exerçam a mesma industria; de explorar um desenho, um modêlo, um processo cujo seja inventor ou cujo inventor lho tenha cedido». (I I)

34 - Para nós, consiste a propriedade industrial no-direito exclusivo de reproduzir com fito de lucro ou de explorar uma producção immaterial ou uma creação da actividade mental, de immediato interesse para a indusiria.

$3 \breve{-C o m}$ este nosso conceito não está em desharmonia o recentissimo trabalho dado á publicidade pelo professor Ramella e no qual se lê :

(11) Goujet ex Merger, Dictionn. de Droit Comm. et Industr. edição de RUden DE Courder, vol. "Propriété industrielle." A mesma noção, qrasi textualmente reproduzida, encontra-se em Michel PElletier Manuel Pratique de Droit Comm. Industr. et artistique, vol. II, vol. "Propriété Industrielle." 
"A propriedade industrial constitue uma das categorias de productos intellectuaes de trabalho protegido pela lei, e está ao lado da propriedade litteraria assegurada ás obras do engenho. São duas formas de propriedade denominadas ambas direitos de autor, que é o complexo dos direitos garantidos pela moderna legislação aos autores de produç̧ões litterarias e artisticas, assim como industriaes, especialmente na parte em que se referem á utilidade material que de taes trabalhos espera o autor auferir.» (I 2)

36.-Enumeram-se entre os elementos da propriedade industrial:

a) As patentes ou privilegios de invenção,

b) As marcas de industria e de commercio,

c) O nome commercial ou industrial,

d) Os desenhos e modelos de fabrica,

e) As insignias, taboletas e razões de com. mercio,

f) As indicações de proveniencia e industriaes.

g) As medalhas, diplomas $€$ outras recompensas

ESBOÇO HISTORICO DA PROPRIEDADE INDUSTRIAL NO BRAZIL

37. - A noção la propriedade industrial, abstracção feita dos seus caracteres communs com a propriedade civil, assignala certamente progresso notavel na evolução do direito. Embora se encontrem na jurisprudencia antiga germens embryonarios dessa instituição, não ha duvidar que sómente nas legisla-

(12) A. Ramella, Tratt. della Propr. Industr., 1909, vol. I n. 2. 
ções modernas ella apparece consagrada com a sancção tutelar do direito positivo.

Isto não significa que não fosse reconhecida pelo direitu antigo, mesmo em data anterior ás compilações justineanas, a faculdade aos fabricantes de assignalar com o proprio nome, assignaturas ou qualquer signal distinctivo as obras de sua producção. Era, porém, antes a marca da propriedade que a propriedade da marca.

38.-Com o desenvolvimento da industria, consequente da sua liberdade proclamada pela Revolução Franceza, tomou incremento o direito, para cada fabricante, de objectivar nos seus productos, fructos do seu trabalho, da sua intelligencia e do seu capital, o cunho da respectiva procedencia. Nada mais justo e mais honesto. $\mathrm{O}$ meio adoptado consistio na appo. sição de um signal caracteristico, de uma marca. Esta, portanto, deveria revestir-se do caracter de uma propriedade e, pelos seus effeitos, propriedade de subido valor.

Tal foi a origem historica da propriedade industrial consistente nas marcas de fabrica.

39. --Não é nosso proposito desenvolver nestas paginas, nem mesmo expôr em ligeiro esboço, o historico dessa instituição no vasto scenario do orbe civilisado. Vamos apenas delinear em rapidos traços as phases principaes que ella tem tido no nosso direito patrio.

40.-Podem estas classificar-se em quatro periodos, a saber:

I $^{\circ}$ A época anterior á decretação da lei $n$. 2.682 de 23 de Outubro 1875 ;

2. Dessa data até á da decretação da lei n. 3.346 de i 4 Outubro de I 887 ; 
$3 \cdot^{\circ}$ De então até á data da "decretação da lei n. 1.236 de 24 de Setembro de I904;

$4^{\circ}$ Dessa data em diante.

41.-O primeiro destes periodos assignala-se pela omissão, judicialmente comprovada, de disposições repressivas das violações attentatorias "a propriedade industrial ou, mais exactamente, dessa " propriedade consistente em marcas de industria e de commercio e nome commercial.

Era, entretanto, tão intensa a necessidade da proteção desses direitos, abertamente conspurcados pela contrafacção e imitação illicita, que surgio á idéa de applicarem se a taes attentados as disposiçōes dos arts. I67, 257, 264 e 306 do Codigo Criminal de I 830 , então vigente, relativos ás figuras juridicas do estellionato, do furto e dd violação da propriedade litteraria e artistica.

Como era curial, não prevaleceo tal alvitre. Luminoso aresto judiciario ( 13 ) poz patente a inopia do direito então em vigor e a impotencia dos juizes e tribunaes para a proteç̧ão dos sagrados direitos da industria.

42.-Decahidos da acção, os industriaes de que se trata endereçaram ao poder legislativo uma representação na qual, fazendo sensivel a lacuna existente no direito patrio, reclamavam a decretação de uma lei que a preenchesse.

- A Commissão de Justiça Criminal da Camara dos Deputados (14) acolheo favoravelmente a petição, julgoư procedente o seu objecto e na sessão de 20

(13) Accordam da Relação da Bahia, de 28 de Julho de 1874. Vid. Direito vol. 5.", pag. 649.

(14) A Cominissào ela composta dos deputados Gomes de Castro, Heraclito Graça e Henrique Rabello, sendo relator o primeiro. 
de Março de I875 apresentou sobre elle desenvolvido e luminoso parecer, concluido com um projecto de lei.

Este foi approvado sem debate em i a discussão na sessão de 20 de Abril e com pequenas modifica: ções, em 2. ${ }^{a}$ discussão, a 28 do mesmo mez e por fim approvado em $3 \cdot^{\text {a }}$ discussão - na sessão de 5 de Junho. Soffreu apenas a impugnação do deputado Alencar Arăripe, que o considerava desnecessario, por não trazer innovação alguma ao direito vigente. A constituição do Imperio garantia a propriedade em toda a sua plenitude, portanto tambem a propriedāde industrial. E não era essa uma garantia méramente theorica, pois para o offendido, além da protecção da lei penal, havia o direito de pedir indemnisação pelo damno causado. Quanto ao direito de marcar os productos para lhes assignalar a procedencia, quem o contestava aos industriaes? Não se fazia necessario para tal fim uma lei permissiva!

A estas objecções respondeu o relactor, cujo discururso, porém, não figura nos Annaes do Parlamento; nem tão pouco os proferido sobre o mesmo assumpto pelo deputado fluminense Duque Estrada Teixeira.

43. - No Senado passou o projecto por luminoso debate nas 'sessões de 2 e 4 de Setembro, enunciando sobre a propriedade industrial, idéas muito acertadas o grande jurisconsulto conselheiro Nabuco, que lhe poz varias emendas.

Adoptadas estas pelás camara vitalicia, volveo o projecto á outra camara, onde fôra iniciado. Nella tiveram approvação todas as emendas do Senádo. Subio o projecto á sanção imperiăll e foi publicado como lei com a data de 23 de Outubro de i 875 .

44.-Embora eivada de imperfeições resultantes, em parte, do assodamento da sua elaboração parlamentar $\longrightarrow$ (pois era grande o empenho de legislar acce-.. 


\section{$-73-$}

leradamente sobre o assumpto), esta lei veio marcar assignalado progresso na elevação da propriedade industrial no Brazil.

Dacta deste ponto a segunda phase historica á qual acima nos referimos.

Os defeitos dessa reforma são circumstanciadamente expostos na Consulta do Conselho de Estado, das secções reuniclas do Imperio e Justiça, de 30 de Novembro de $\mathrm{I} 884$, relator o conselheiro Affonso Celso.

As suas vantagens consistiram em collocar a legislação brazileira no nivel dos progressos conquistados sobre aquella especialidade juridica pelo direito das nações mais adiantadas.

45.-Aconteceo, porém, que, sendo sobre tal objecto, em intensa evolução, muito celeres as transformações do direito, mal havia decorrido um lustro após aquella reforma e já estava ella a pedir complementos e modificações.

A co-participação do Brazil na Convenção de Paris de 20 de Março de 1883 , impondo-lhe as obrigações solidariamente contrahidas pelos Estados signatarios daquella convenção diplomatica, exigia prompta reforma no seu direito interno, omisso em varios pontos sobre os quaes versavam as referidas obrigaçóes.

46.-Nessa conjectura, preferio o poder executivo, que tinha deixado até então de regulamentar a lei n. 2.682 de 1875 , promover a reforma della por acto legislativo a dar-lhe regulamento para que fosse melhor executada.

Aliás estava ella desde muito em execução e mesmo dessa pratica haviam resultado a comprovação e os inconvenientes de varias lacunas já indicadas na consulta do Conselho de Estado, e de outras que então somente se relevaram. 


\section{$-74-$}

Essa lei foi commentada numa interessante monographia pelo Dr. Didimo Veiga Junior.

47. - Por Aviso de 6 de Fevereiro de i 884, foram encarregadas as seç̧ões reunidas dos Negocios do Imperio e da Justiça do Conselho do Estado de elaborar um projecto de lei que harmonisasse a legislação patria com os deveres decorrentes para o Brazil da sua adhesão á Convenção de Paris, promulgada pelo Decreto n. 9.233 de 28 de Julho de 1884 .

Desta incumbencia desempenharam-se as seç̧ões reunidas, elaborando um trabalho que o governo acceitou e foi pelos senadores Affonso Celso e Leão Velloso offerecido á consideração do Senado na sessão de 27 de Maio de 1885 .

48.- O projecto entrou em $\mathrm{I}^{\mathrm{a}}$ discussão na camara vitalicia na sessão de 27 de Julho de 1885 , na qual sobre elle occupuram a tribuna os senadores Corrêa e Affonso Celso. $\mathrm{Na}$ sessão de 28 proseguio o debate, voltando á tribuna o senador Corrêa, que suscitou algumas objecções ao projecto, as quaes foram com vantagem refutadas pelo senador Affonso Celso. Tambem propuzeram varias duvidas os conselheiros Paranaguá e Junqueira, ás quaes respondec com segurança e brilhantismo o conselheiro Affonso Celso, revelando profundo conhecimento do assumpto.

Abstemono-nos, por agora, de analysar o objecto das controversias suscitadas, por que dellas teremos apportunamente de nos occupar, por mais de uma vez, nas paginas deste livro.

49.-Adoptado, finalmente, pelo Senado, com algumas emendas, foi o projecto enviado em 4 de Setembro de 1885 á Camara dos Deputados, onde por quasi dois annos dormio esquecido na pasta da Commissão de Obras Publicas, Commercio e Industria. 
Veio a debate na sessão de i 8 de Julho de I 887 , amparado por parecer daquella commissão, que lhe propoz duas emendas, uma das quaes reprimindo penalmente o uso de marcas com indicação de falsa proveniencia.

Approvado nas duas discussões regimentaes com as emendas mencionadas, voltou o projecto ao Senado, que o acceitou naquelles termos, em sessão de I 2 de Outubro de i887. Nesse mesmo dia subio á sanç̧ão imperial.

Foi sanccionado, promulgado e publicado como lei, pelo Decreto n. 3.346 de i 4 de Outubro de i 887

O seu regulamento não se fez esperar; pois foi approvado por Decreto n. 9.828 de 3 I de Dezembro de 1887 .

כ0.-Um mez depois, o sr. conselheiro Affonso Celso, o autor mental da reforma, dava á publicidade excellente livro em que expuha o pensamento do legislador e estudava em face do direito novo, elucidado pelas liç̧ões dos jurisconsultos estrangeiros, pela legislação parallela dos outros póvos e pela doutrina dos tribunaes (I 5 ).

Por muito tempo, esse trabalho juridico tornou-se em nosso fôro precioso guia nas acções referentes a marcas industriaes e nome commercial, e ainda hoje não é de somenos a sua utilidade. Claro, methodico, obedecendo em todos os conceitos ao mais judicioso criterio, essa importante monographia tem poderosamente contribuido em nosso meio para o progresso das idéas sobre a propriedade industrial.

51.-Com a decretação da reforma de i 887 , abre-se o terceiro periodo na evolução do direito industrial patrio.

(15) Affonso Celso (inais tarde. Visconde de Ouro Preto) Marcas Industriaes e Nome Commercial, 188\%, Rio de Janeiro. 


\section{$-76-$}

A transformação politica pela qual passou o Brazil em $\mathrm{r} 88_{9}$ e a consequente instituição do regimen federativo influenciaram poderosamente, sobretudo quanto ao direito formal, na nova especialidade juridica.

Varias questões surgiram, suscitaram-se diversas duvidas quanto á competencia do fôro para a propositura das acções sobre marcas de fabrica.

52.-A Constituição da Republica havia assentado entre os seus principios fundamentaes a instituição da justiça federal organisada pela União, ao passo que deixava aos Estados federados o direito de constituirem e organisarem a justiça local.

Estabelecida esta dupla jurisdicção, qual o fôro competente para conhecer e julgar as questões refe. rentes ás marcas industriaes?

53.-Este ponto, que opportunamente havemos de estudar, suscitou sérias divergencias até, ou principalmente, no proprio recinto do Supremo Tribunal Federal.

Longe de solvel-o, a legislação secundaria não veio senão complical-o ainda mais, porque se the oppunha com razão que a materia é de natureza constitucional e não póde ser modificada pelo legislador ordinario.

5'4.-Esta questão e bem assim a inefficacia da penalidade comminada pela lei de 1887 e transplantada para o Codigo Penal de 1890 reclamavam novos dispositivos na legislação industrial.

Os direitos da industria legitima não se consideravam sufficientemente garantidos em seus fundamentos pois grande numero de processos por ella movidos contra os contrafactores das suas marcas eram annullados na instancia superior. 
$\check{5} 5-\mathrm{E}$ assim tripudiava vencedora a fraude, motejando das comminações legaes. Procurava mesmo inverter no espirito publico as posições juridicas, apresentando-se os contrafactores como legitimos representantes da industria nacional perseguidos pela chantage de fabricantes extrangeiros, ávidos de excluirem a concorrencia do seu trabalho e ciosos do seu progresso, etc., etc.

כ̋6.- Acompanhando corrente opposta a essa desordem moral, talentoso representante da nação, em sessão da Camara dos Deputados de 23 de Novembro de I903, apresentou um projecto de reforma da lei de i4 de Outubro de 1887 (16), abrindo assim a quarta phase progressiva da propriedade industrial no direito brazileiro.

Em eloquente e bem ponderada oração, conseguio o autor do projecto, ao passo que revelava pleno conhecimento da materia, demonstrar a deficiencia do direito patrio em vigor e fundamentar as modificações e innovações que propunha.

57 - As idéas capitaes da refórma que aliás foram acceitas pelo Congresso, são as seguintes :

I. ${ }^{a}$ A declaração de que as marcas podem ser usadas tanto no producto industrial como no respectivo envolucro, recipiente, etc.

2. ${ }^{\text {a }}$ O restabelecimento da pena de prisão, além da de multa, contra os violadores da propriedade industrial $(\mathrm{I} 7)$.

(16) Di. Germano Hasslocher, deputado ao Congresso Nacional pelo Estado do Rio Grande do Sul.

(17) Essa penalidade, comminada pelas leis n. 2.682 de 1875 e 3.346 de 1887, havia sido supprimida no Codigo Penal de 1890. Em boa hora a restabeleceo o legislador patrio de 1904.

Estão a clamar por analoga reforma as disposições do Codigo sobre patentes de invenção e propriedade litteraria e artistica. 
$3 .^{a} \quad$ Mais clara e completa enumeração dos casos puniveis de violação das marcas de fabrica e nomes commerciaes ;

$4 .^{\mathrm{a}}$ Maior efficacia no exercicio das deligencias de busca e apprehensão, ampliando-as, facilitando-as e tornando-as menos precaria, mais celeres e menos onerosas;

$5 .^{\mathrm{a}}$ Determinando que a apprehensão de productos revestidos de marcas contrafeitas ou illicitamente imitadas deve ser feita ex-officio nas alfandegas no acto de conferencia dos productos, e pelos fiscaes do imposto de consumo;

6. ${ }^{\text {a }}$ A prisão do falsificador no acto da apprehensão, a qual abrangerá tudo quanto seja destinado directa ou indirectamente a auxiliar a contrafacção;

$7 .{ }^{\text {a }}$ A responsabilidade dos donos das officinas onde se preparar o genero falsificado; da pessoa que o tiver sob sua guarda; do vendedor e do dono da casa onde estiver collocados os productos;

8. ${ }^{\mathrm{a}}$ A determinação, coherente com as normas constitucionaes, da competencia da justiça federal ou da do Districto federal e dos Estados, conforme a natureza da acção, a nacionalidade das marcas e as partes interessadas no processo;

9. ${ }^{\mathrm{a}} \quad$ A condemnação do réu á satisfação do damno causado, na mesma sentença condemnatoria, em acção criminal (18).

(18) Sem prejuizo, naturalmente, do direito para o offendido de intentar, independente de processo criminal, ‘cção civel de indemnisação. Esta parte do prnjecto não foi acceita pelo Senado, e assim ficou prevalecendo no art. 20 da Lei coherentemente com a doutrina do art. 70 do Cudigo Penal, o preceito já antes consagrado no art. 19 da lei n. 3.346 de 1887 cuja materia, aliás, é de direito civil e nada tem de peculiar ao 
58. - O projecto foi approvado sem debate na Camara dos Deputados.

Remettido ao Senado, ahi foi ligeiramente emen: dado no sentido de

a) melhor assentarem-se os principios reguladores da competencia judiciaria e

b) supprimir-se a disposição relativa á condemnação pelo juiz criminal á satisfação do damno causado pela violação da marca.

Approvado nestes termos, o projecto voltou á Camara dos Deputados, que o acceitou com as emendas e fel-o subir a sanç̧ão do presidente da Republica.

Este decreto legislativo converteo-se na Lei $n$. I. 236 de 24 de Setembro de 1904.

O seu regulamento, que algo se fez esperar, foi approvado pelo Decreto n. 5.424 , de 10 de Janeiro de 1905 .

59.-Como se vê, a reforma foi decretada acceleradamente e quasi sem discussão, não ousamos dizer que sem estudo, em ambas as casas do Congresso Nacional.

Deste facto ella não pouco se resente. A sua redacção muita deixa a desejar, e mesmo o dispositivo contém defeitos e lacunas que, com mais detido exame poderiam delles ser escoimados.

Conviria, por exemplo, que se simplificassem as complicadas operações do registro nacional das marcas alvo de justificada critica de notavel industrialista ( ( 9 ). Tambem provoca reparo que a nova lei não contenha uma só disposição sobre o registro internacional. E

(19) Malllard de Marafi, Grand Diction. de la Propr. Indust. vol. «Depôt de la marque». 
tão grave foi essa omissão, que o poder executivo procurou, incompetentemente corrigil-a no regulamento.

60. - Acerca desta ultima phase do direito patrio sobre marcas de industria e de commercio foram dados á publicidade dois livros, sendo um, de pequeno folego, pelo Dr. Gouvêa Natividade, e outro bastante desenvolvido, pelo Dr. Bento de Faria, a quem as nossas lettras juridicas são já devedoras de muitos e importantes trabalhos (20).

Estas monographias e bem assim varios trabalhos juridicos, de caracter propriamente forense, publicados em desempenho do serviço profissional por illustres advogados brazileiros teem offerecido regular contribuição para o estudo desta materia.

Dentre as publicações a quem acabamos de alludir é de justiça destacarmos as dos nossos distinctos collegas, do fôro fluminense, Drs. Tarquinio de Souza Filho, Inglez de Souza, Francisco de Castro Junior, Heitor Diniz Cordeiro, Sá Vianna e Sancho de Barros Pimentel; e do fôro paulistano,-Pedro de Toledo, Augusto Leite, Gomes Ribeiro, Adolfo Gordo, Paulo Dias e Estevam de Oliveira.

Pedimos venia para nesta lista accrescentar, em ultimo lugar, o mome de um dos autores deste livro que desde muito se dedica a estes estudos e tem já editado em opusculos nada menos de dez memoriaes ou razões de advogado, e bem assim em revistas juridicas, bom numero de artigos de doutrina e outros sobre questões de processo referentes á propriedade industrial.

(20) Francisco Marcondes de G. Natitidade, Marca de fabrica $e$ de Commercio,-1906. S. Paulo.-Dr. Antonio Bento de Faria, Das Marcas de fabrias e de conmercio e do Nome commercial. 1906.-Rio de Janeiro. 


\section{$-8 \mathrm{I}-$ \\ V I}

FONTES DO DIREITO INDUSTRIAL BRAZILEIRO

61.-As fontes do direito industrial patrio podem classificar-se em fontes com força extrinseca, com autoridade de lei; e fontes com força intrinseca, sem autoridade de lei.

O direito emanado daquellas fontes é obrigatorio quand même, superior ao criterio do juiz que o $t \in m$ de applicar; os preceitos decorrentes destas ultimas são sujeitos á apreciação judicial, e a sua applicabilidade resulta antes dos seus fundamentos doutrinarios e da analogia dos casos, do que propriamente da sua origem.

62. - Tambem se denominam as primeiras - fontes directas, essenciaes ou elementares, estas ultimas fontes indiretas ou subsidiarias.

Estas denominações, porẻm, em nosso conceito, não se adaptam á mesma classificação, sendo differente o principio discriminador; seria necessario estabelecerem-se sub-divisóes.

$\mathrm{Na}$ verdade, fontes directas e essenciaes do direito industrial - seriam sómente as leis patriaes e convenções diplomaticas particularmente destinadas a compor essa especialidade juridica, todas as outras assumiriam o caracter de fontes indirectas e subsidiarias.

63.-Entre as fontes com autoridade obrigatoria e força de lei ênumeram-se.

a) 'A legislação industrial brazileira;

b) Os tratados e convenções internacionaes sobre objecto de direito industrial, incorporados por decreto á legislação brazileira;

c) O codigo e mais legislação commercial; 
d) $\mathrm{O}$ direito civil patrio;

e) $\mathrm{O}$ direito publico constitucional;

f) O codigo penal;

g) O direito judiciario e processual da União e dos Estados.

64.-As fontes subsidiarias, com força méramente intrinseca, sem caracter obrigatorio, do direito industrial patrio são:

a) A legislação industrial extrangeira, inclusive o respectivo direito costumeiro;

b) $\mathrm{O}$ direito romano;

c) A jurisprudencia dos tribunaes $a$ ) patrios e $b$ ) extrangeiros ;

d) Os documentos da elaboração legislativa, a saber-pareceres das commissões parlamentares, consultas do conselho de Estado, discussões na Camara dos Deputados e no Senado;

e) A doutrina dos jurisconsultos a) patrios e $b$ ) extrangeiros, colhida em obras didacticas, respostas a consultas e trabalhos forenses.

J. L. DE Almeida Nogueira. 